\title{
Research Paper: Role of Nitric Oxide in the Antipruritic Effect of WIN 55,212-2, a Cannabinoid Agonist
}

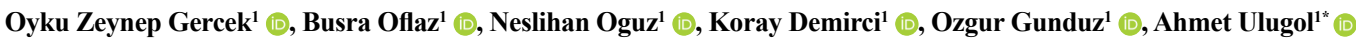

1. Department of Medical Pharmacology, Faculty of Medicine, Trakya University, Turkey.

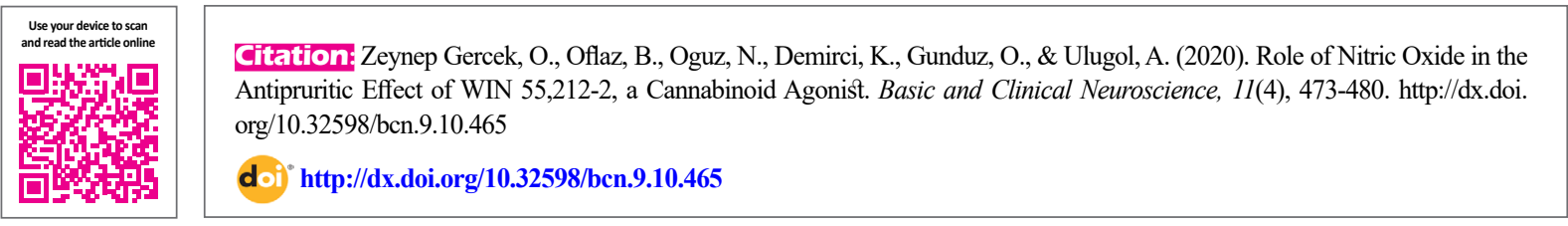

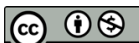

Article info:

Received: 30 Mar 2018

First Revision: 25 Apr 2018

Accepted: 29 Apr 2019

Available Online: 01 Jul 2020

Keywords:

Cannabinoid system, Nitric oxide, Pruritus, Serotonin,

WIN 55,212-2

\section{A B S T RA C T}

Introduction: For centuries, cannabinoids are known to be effective in pain relief. Itch is an unpleasant sensation that provokes a desire to scratch. Since itch and pain are two sensations sharing a lot in common, we aimed to investigate whether the cannabinoid agonist WIN 55,212-2 reduces serotonin-induced scratching behavior and also observe whether modulation of Nitric Oxide (NO) production mediates the antipruritic effect of WIN 55,212-2.

Methods: Scratching behavior is induced by intradermal injection of serotonin $(50 \mu \mathrm{g} / 50$ $\mu \mathrm{L} /$ mouse) to BALB/c mice. The cannabinoid agonist WIN 55,212-2 (1, 3, $10 \mathrm{mg} / \mathrm{kg}$, IP) was given $30 \mathrm{~min}$ before serotonin injection. To observe the effect of NO modulation on the antipruritic effect of cannabinoids, the endothelial nitric oxide synthase (NOS) inhibitor L-NAME (3 mg/kg, IP), the neuronal NOS inhibitor 7-nitroindazole ( $3 \mathrm{mg} / \mathrm{kg}$, IP), and the NO precursor L-arginine $(100 \mathrm{mg} / \mathrm{kg}$, IP) were administered together with WIN 55,212-2.

Results: WIN 55,212-2 reduced serotonin-induced scratches at higher doses (3, $10 \mathrm{mg}$ / $\mathrm{kg} ; \mathrm{P}<0.0001)$. The endothelial NOS inhibitor L-NAME, the neuronal NOS inhibitor 7-nitroindazole, and the nitric oxide precursor L-arginine did not influence the antipruritic action of WIN 55,212-2. When NO modulators were used alone, only the neuronal NOS inhibitor 7-nitroindazole attenuated serotonin-induced scratches $(\mathrm{P}<0.0001)$.

Conclusion: Our findings indicate that exogenous cannabinoids may attenuate serotonininduced scratches and NO does not mediate the antipruritic effect of WIN 55,212-2. On the other hand, neuronal NOS inhibition may play a role in the production of serotonin-induced scratches.

\section{* Corresponding Author:}




\section{Highlights}

- Exogenous cannabinoids reduce serotonin-induced scratching behavior.

- Nitric oxide does not mediate the antipruritic action of cannabinoids.

- Cannabinoids have the potential to be used as antipruritic drugs.

\section{Plain Language Summary}

Cannabinoid drugs are not used effectively due to their potential drug abuse and side effects. For centuries, cannabinoids are known to exert analgesic actions, but they also produce antipruritic effects. There are numerous studies on the mechanisms of the analgesic effects of cannabinoids; however there are only a few research on their antipruritic mechanism of action. In this study, we observed the modulatory role of nitric oxide in the effect of cannabinoids on serotonininduced scratches which nitric oxide did not play role in this action. We induced scratching behavior by administering serotonin intradermally. Then we injected the cannabinoid agonist WIN 55,212-2 and observed the reduction of the scratching behavior. Afterwards, we administered an endothelial nitric oxide synthase inhibitor, a neuronal nitric oxide synthase inhibitor, and a nitric oxide precursor and showed that nitric oxide does not mediate the antipruritic effects of WIN 55,212-2. Whatever the mechanism of action, cannabinoids have the potential to be used as antipruritic drugs, especially if their side effects are reduced.

\section{Introduction}

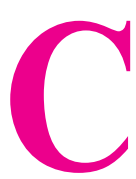

annabinoids are chemicals that produce their effects mostly via activating cannabinoid receptors (CB1, CB2); they include phytocannabinoids, synthetic cannabinoids, and endocannabinoids (Maccarrone et al., 2015; Olah, Szekanecz, \& Biro, 2017; Ulugol, 2014). The analgesic activity of cannabinoids has been known for centuries; however, these drugs could not be used efficiently in the clinics due to their potential drug abuse and unwanted central side effects, including the development of drug tolerance and addiction. Following many successful clinical trials, cannabinoids have been approved for indications such as neuropathic pain, multiple sclerosis, and so on first in the USA and Canada, and then in many European countries in recent years (Grotenhermen \& Muller-Vahl, 2012; Lucas, 2012; Ulugol, 2014). The number of approved indications and countries cannabinoids are used therapeutically is expected to increase in the years ahead.

Pruritus (itch), a common unpleasant symptom, is seen not only in skin diseases but also in systemic disorders. Pain and itch share a lot in common in terms of pathophysiology, which suggests why pain mechanisms should also be evaluated when itch is being investigated (Ross, 2011; Schmelz, 2010). Recently, similar to pain, not only peripheral mechanisms but also central mechanisms have been suggested to play important roles in itch. These new notions have started to change the approaches to the therapy of pruritus (Cevikbas, Steinhoff, \& Ikoma, 2011). Understanding the detailed mechanisms of itch will contribute to the development of more efficient antipruritic medications with fewer side effects.

The number of studies regarding the analgesic effects of cannabinoids is quite remarkable. Nevertheless, the effects of cannabinoids on itch have not been investigated sufficiently despite the similarities between pain and itch mechanisms. Cannabinoid receptor agonists have been shown to reduce itch behavior, whereas cannabinoid receptor antagonists like rimonabant increased itch behavior dose-dependently in mice (Darmani \& Pandya, 2000). Other research studies also pointed out that the brain penetrating CB1 inverse agonist rimonabant creates itch sensation, and this effect is reduced by cannabinoid receptor agonists (Janoyan, Crim, \& Darmani, 2002; Schlosburg, O'Neal, Conrad, \& Lichtman, 2011). Furthermore, it is determined that the peripheral application of the synthetic cannabinoid HU210 suppresses histamine-induced responses in human skin (Dvorak, Watkinson, McGlone, \& Rukwied, 2003). In addition to these studies, few studies have carried out on the role of the endocannabinoid system in itch behavior (Schlosburg, Boger, Cravatt, \& Lichtman, 2009; Spradley, Davoodi, Gee, Carstens, \& Carstens, 2012; Tosun, Gunduz, \& Ulugol, 2015).

Nitric Oxide (NO) is produced from L-arginine by Nitric Oxide Synthase (NOS) and regarded as a neuronal messenger and a modulator in the central nervous system (Snyder \& Bredt, 1991). NOS has at least three isoforms: endothelial 
(eNOS), neuronal (nNOS), and inducible (iNOS) (Boucher, Moali, \& Tenu, 1999). NO is known to take part in many physiological and pathological phenomena; elevated NO levels are observed not only in experimental models of inflammation and hyperalgesia (Nakamura, Fujita, \& Shiomi, 1996), but also in several clinical neurological disorders, including Alzheimer disease, Parkinson disease, multiple sclerosis, and so on (Duncan \& Heales, 2005; Zhang, Diao, Hua, Wang, Han, \& Yin, 2017). Taking into account the similarities between pain and itch, the contribution of NO to pruritic states can also be expected. A few studies indicate that NO production is increased in both experimental itch models and clinical pruritic diseases such as psoriasis and atopic dermatitis (Andoh \& Kuraishi, 2003; Ormerod et al., 1998; Taniuchi et al., 2001), but its involvement in cannabinoid-induced antipruritic action is unknown.

In our study, we aimed to examine whether the non-selective cannabinoid CB1 and CB2 agonist WIN 55,212-2 diminish serotonin-induced scratches, which we have shown in our previous work (Todurga, Gunduz, Karadag, \& Ulugol, 2016), and also determine whether NO is involved in the antipruritic effect of WIN 55,212-2. Revealing the mechanisms of these effects of cannabinoids may contribute to their utility as novel antipruritic agents.

\section{Materials \& Methods}

\subsection{Animals and ethics}

A total of 80 male BALB/c mice (Center of the Laboratory Animals, Trakya University), 3-4 months old and weighing 20-30 g, were used in the experiments ( $\mathrm{n}=8$ for each group). Mice were housed under controlled 12-12 $\mathrm{h}$ light-dark cycles at the temperature of $21 \pm 2^{\circ} \mathrm{C}$ with water and food available ad libitum. Adequate measures were taken to minimize pain or discomfort, and the Animal Care Ethics Committee of Trakya University approved all experimental protocols of this study.

\subsection{Serotonin-induced scratching behavior}

To provoke scratching behavior, serotonin $(5 \mu \mathrm{g})$ was administered intradermally in a volume of $50 \mu \mathrm{L}$ into the preshaved rostral part of the back of the mice. Immediately after serotonin injection, the animals were put into a transparent plexiglass cylinder individually, and their behaviors were videotaped for $30 \mathrm{~min}$ under quiet circumstances. In general, the mice produced several scratches per second, and such manner was considered as one bout of scratching. The video was replayed to calculate the number of bouts of scratching, similar to our earlier studies (Gunduz et al., 2015; Saglam, Gun- duz, \& Ulugol, 2014; Todurga, Gunduz, Karadag, \& Ulugol, 2016; Tosun, Gunduz, \& Ulugol, 2015).

\subsection{Rotarod assessment}

Since it is known that cannabinoids may have adverse effects on locomotor activity, the effect of WIN 55,212-2 on motor function was evaluated by the Rotarod test; the same test was also applied to NO modulators. Time course to fall of the mice was documented. Before assessments, a cut-off time of $180 \mathrm{~s}$ and a speed of $16 \mathrm{rpm}$ were adjusted. Rotarod tests were performed immediately before serotonin injections.

\subsection{Experimental protocol}

While group 1 was selected as the vehicle group, groups 2, 3, and 4 received respective doses of the cannabinoid receptor agonist WIN 55,212-2 (1,3, $10 \mathrm{mg} / \mathrm{kg}$, IP) $30 \mathrm{~min}$ before serotonin injection.

In groups 5-7, to evaluate the effect of NO modulation on the antipruritic effect of cannabinoids, the non-selective NOS inhibitor L-NAME ( $3 \mathrm{mg} / \mathrm{kg}$, IP), the nNOS inhibitor 7-nitroindazole ( $3 \mathrm{mg} / \mathrm{kg}, \mathrm{IP})$, and the NO precursor L-arginine $(100 \mathrm{mg} / \mathrm{kg}$, IP) were administered 10 min before WIN 55,212-2, respectively.

In groups 8-10, NOS inhibitors L-NAME (3 mg/kg, IP) and 7-nitroindazole ( $3 \mathrm{mg} / \mathrm{kg}, \mathrm{IP})$ and the NO precursor L-arginine $(100 \mathrm{mg} / \mathrm{kg}$, IP) were given, respectively. Thus, we attempted to confirm the cannabinoid action on serotonin-induced scratching behavior and investigate the mediatory effect of NO in this antipruritic effect.

\subsection{Drugs}

Serotonin hydrochloride was dissolved in $0.9 \%$ saline, while WIN 55,212-2, L-NAME, 7-nitroindazole, and Larginine were dissolved in 20\% DMSO, $1 \%$ Tween $80,1 \%$ ethanol and $78 \%$ saline. This composition is also used in the vehicle group. All of the drugs were purchased from Sigma-Aldrich. Drug doses and treatment times were determined from our previous research studies (Gunduz, Topuz, Karadag, \& Ulugol, 2016; Ulugol et al., 2002; Ulugol, Topuz, Gunduz, Kizilay, \& Karadag, 2016).

\subsection{Statistical analysis}

Bartlett's test was used to test Gaussian distribution. To assess the significance of any difference, one-way ANOVA test followed by the Bonferroni post hoc test was performed. Results were expressed as Mean \pm Standard Error of the Mean. A $\mathrm{P}<0.05$ was considered significant. GraphPad Prism 6.0 was used for statistical analysis and to plot the graphs. 


\section{Results}

3.1. Effect of WIN 55,212-2 on serotonin-induced scratching behavior

Although WIN 55,212-2 reduced the number of scratches at its lowest dose $(1 \mathrm{mg} / \mathrm{kg})$, this effect was not statistically significant. WIN 55,212-2 elicited significant antipruritic activity at higher doses $(3,10 \mathrm{mg} / \mathrm{kg}, \mathrm{P}<0.0001$, Figure 1$)$.

3.2. Effect of NO modulators on the antipruritic activity of WIN 55,212-2

NOS inhibitors L-NAME (3 mg/kg, IP) and 7-nitroindazole $(3 \mathrm{mg} / \mathrm{kg}$, IP) and the NO precursor L-arginine $(100 \mathrm{mg} / \mathrm{kg}, \mathrm{IP})$ did not change the antipruritic activity of WIN 55,212-2 (Figure 2). When NO modulators are used alone, only nNOS inhibitor 7-nitroindazole (3 mg/ $\mathrm{kg}$, IP) significantly reduced the number of scratches produced by serotonin $(\mathrm{P}<0.0001$, Figure 2$)$.

\subsection{Effects of WIN 55,212-2 and NO modulators on locomotor performance}

WIN 55,212-2 disrupted motor function at its highest dose $(10 \mathrm{mg} / \mathrm{kg}$; $\mathrm{P}<0.0001$, compared with the control, Figure 3). NOS inhibitors L-NAME (3 $\mathrm{mg} / \mathrm{kg}$, IP) and 7-nitroindazole (3 $\mathrm{mg} / \mathrm{kg}, \mathrm{IP})$ and the NO precursor Larginine $(100 \mathrm{mg} / \mathrm{kg}$, IP) did not exert any effect on locomotor activity (Figure 3 ).

\section{Discussion}

As mentioned earlier in the introduction, research on the analgesic effects of cannabinoids has been carried out many times. However, despite many established simi- larities between the mechanisms of pain and itch (Cevikbas, Steinhoff, \& Ikoma, 2011; Ross, 2011; Schmelz, 2010), the effects of cannabinoids on itch has remained under-researched. The few existing studies on the matter demonstrated that cannabinoid receptor agonists decrease scratching behavior. Also, cannabinoid receptor antagonists like rimonabant, and a brain penetrating CB1 inverse agonist, dose-dependently increase drug-induced scratches (Darmani \& Pandya, 2000; Janoyan, Crim, \& Darmani, 2002; Schlosburg et al., 2011; Todurga et al., 2016). Peripheral administration of the potent synthetic cannabinoid HU210 has also been reported to suppress histamine-induced scratches (Dvorak et al., 2003). In accordance with this research and our previous report (Todurga et al., 2016), this study indicates that the cannabinoid receptor agonist WIN 55,212-2 diminishes serotonin-induced scratches dose-dependently. WIN 55,212-2 caused an insignificant decrease in the number of scratches at the dose of $1 \mathrm{mg} / \mathrm{kg}$, whereas it almost ceased scratching behavior at higher doses (3 and $10 \mathrm{mg} / \mathrm{kg}$ ).

NO modulates neuronal function and contribute to various biological tasks in the central nervous system. Moreover, the influence of NOS system on cannabinoid activity has been shown; activation of cannabinoid receptors by anandamide led to NO production (Prevot et al., 1998), and $\mathrm{CB} 1$ receptors stimulated cyclic GMP production in neuronal cells (Carney et al., 2009; Jones, Carney, Vrana, Norford, \& Howlett, 2008). NO has also been suggested to play important roles in the development of tolerance to some effects of cannabinoids. It has also been indicated that NO is involved in the development of tolerance to the hypothermic and catalepsy effects of cannabinoids (Azad et al., 2001; Spina, Trovati, Parolaro, \& Giagnoni, 1998), whereas a negligible contribution to cannabinoid

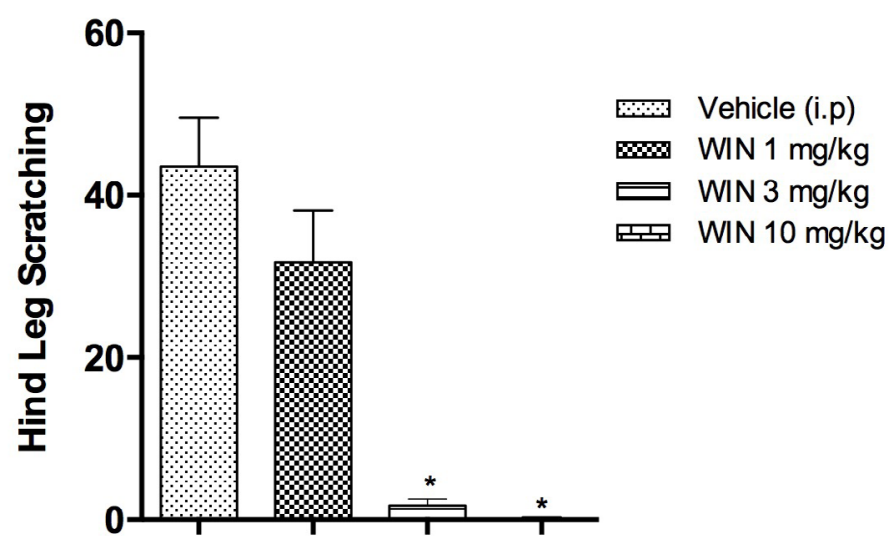

NEUR:SCIENCE

Figure 1. Effects of systemic administration of the cannabinoid agonist WIN 55,212-2 (1, 3, $10 \mathrm{mg} / \mathrm{kg}$, IP) on serotonin-induced scratches. ${ }^{*} \mathrm{P}<0.0001$, compared with the control. 


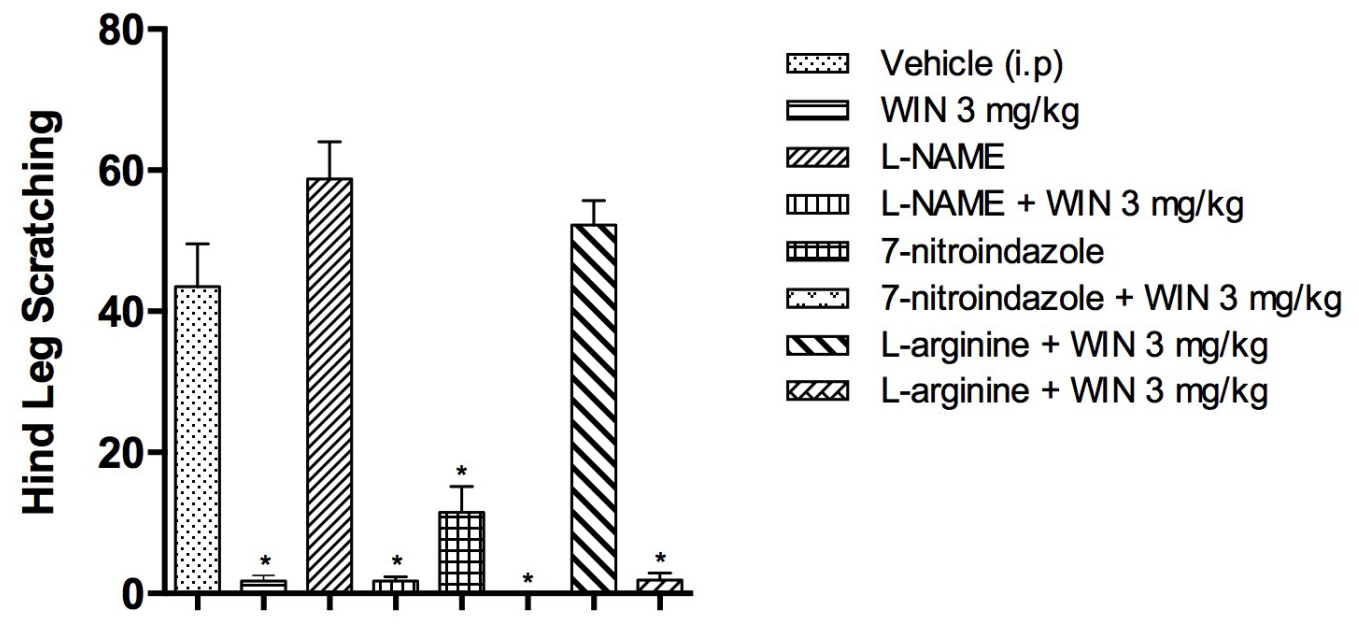

NEUR SCIENCE

Figure 2. Effects of the non-selective NOS inhibitor L-NAME $(3 \mathrm{mg} / \mathrm{kg}$, IP), selective nNOS inhibitor 7-nitroindazole $(3 \mathrm{mg} / \mathrm{kg}$, IP) and the NO precursor L-arginine $(100 \mathrm{mg} / \mathrm{kg}$, IP) on serotonin-induced scratches and the antipruritic effect of WIN 55,212-2 (3 mg/kg, IP). * $\mathrm{P}<0.0001$, compared with the control.

analgesic action has been proposed (Azad et al., 2001; Spina et al., 1998; Thorat \& Bhargava, 1994). In contrast, it has been suggested that L-arginine/NO pathway is involved in the development of tolerance to the analgesic action of the cannabinoid agonist WIN 55,212-2 (Banafshe, Ghazi-Khansari, \& Dehpour, 2005). Given the similarities between the mechanisms of pain and itch, we observed that NO modulation did not influence the antipruritic effect of cannabinoids. Neither endothelial and neuronal NOS inhibitors nor the NO precursor had any effect on the antipruritic action of the cannabinoid receptor agonist WIN 55,212-2. Thus, NO does not play any role in the antipruritic effect of cannabinoids.
Administration of NOS inhibitors and the NO precursor L-arginine on their own revealed different results on serotonin-induced scratches. Neither the non-selective NOS inhibitor L-NAME nor the NO precursor L-arginine had any effect on serotonin-induced scratches. However, the nNOS inhibitor 7-nitroindazole significantly reduced serotonin-induced itch behavior. In another research, in line with our findings, L-NAME had no effect on serotonin-induced scratches, whereas the iNOS inhibitor aminoguanidine prevented itching behavior. Researchers pointed to the involvement of NO in serotonin-induced itching and highlighted the importance of iNOS in the process, yet they had not used

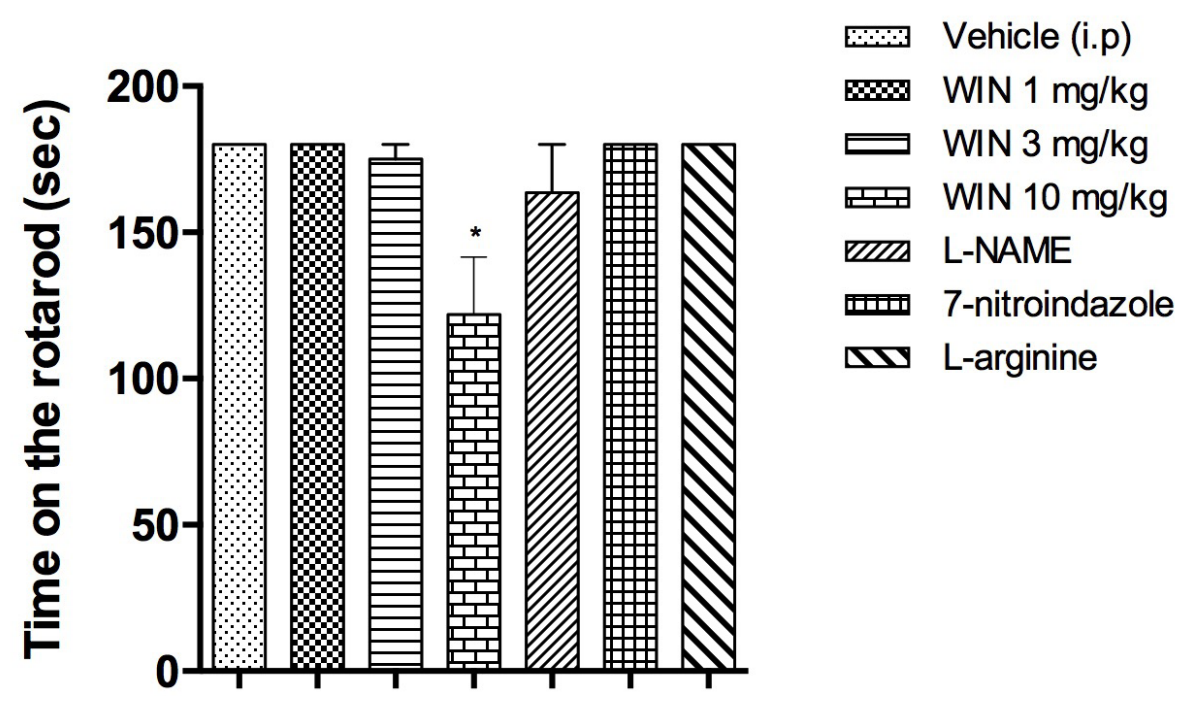

NEUROSCIENCE

Figure 3. Effects of WIN 55,212-2 (1, 3, $10 \mathrm{mg} / \mathrm{kg}$, IP), L-NAME (3 mg/kg, IP), 7-nitroindazole (3 mg/ $\mathrm{kg}$, IP) and L-arginine $\left(100 \mathrm{mg} / \mathrm{kg}\right.$, IP) on locomotor performances. ${ }^{*} \mathrm{P}<0.0001$, compared with the control. 
nNOS inhibitors (Ostadhadi, Haj-Mirzaian, Azimi, Mansouri, \& Dehpour, 2015). Another report concluded that NO/cGMP pathway mediated chloroquine-induced itching and that specifically nNOS inhibition had a role in the process (Foroutan, Haddadi, Ostadhadi, Sistany, \& Dehpour, 2015). Conclusions from these studies are consistent with our results, all suggesting the importance of nNOS inhibition in experimental itch models. It should also be known that the involvement of eNOS cannot be excluded since 7-nitroindazole also inhibits eNOS at higher doses (Ayajiki, Fujioka, Okamura, \& Toda, 2001).

Our findings show that intraperitoneal injection of the cannabinoid receptor agonist dose-dependently decreased serotonin-induced scratching. Mechanism of action of WIN 55,212-2 may include both cannabinoid CB1 and or $\mathrm{CB} 2$ receptors since it is a non-selective $\mathrm{CB} 1 / \mathrm{CB} 2$ agonist. Based on the currently presented data, it cannot be decided whether the actions are realized at the level of the central nervous system or already at the periphery. Peripherally restricted $\mathrm{CB} 1$ agonists could have been used to minimize central side effects, but in this case, peripheral side effects should be taken into consideration and this was not the purpose of this study. Another possible mechanism for cannabinoids is that they may also inhibit Transient Receptor Potential (TRP) channels, especially TRPV1, which plays an important role in sensing itch as well as pain (Morita et al., 2015; Ross, 2011; Schmelz, 2010). In our study, neither the endothelial and the neuronal NOS inhibitors nor the NO precursor influenced the antipruritic action of cannabinoids. On the other hand, the neuronal NOS inhibitor decreased scratching when used alone. We concluded that NO does not mediate the antipruritic action of cannabinoids and neuronal NOS inhibition plays a role in serotonin-induced itching. Whatever the mechanism of action, we believe that cannabinoids have the potential to be used as antipruritic drugs, if their side effects can be reduced.

\section{Ethical Considerations}

\section{Compliance with ethical guidelines}

Adequate measures were taken to minimize pain or discomfort, and "Animal Care Ethics Committee" of Trakya University approved all experimental protocols of this study (TUHADYEK-2015/43).

\section{Funding}

This research was supported by Trakya University Research Council (TUBAP-2015/198).

\section{Authors' contributions}

Conceptualization: Ozgur Gunduz, Ahmet Ulugol: Methodology: Investigation, Funding Acquisition: Resources: All authors; Writing - original draft, writing - review \& editing: Ozgur Gunduz, Ahmet Ulugol; Supervision: Ahmet Ulugol; All authors have read and approved the manuscript before submission.

\section{Conflict of interest}

The authors declare no conflict of interest.

\section{Acknowledgments}

We thank K. Duvan-Aydemir for technical assistance in behavioral testing.

\section{References}

Andoh, T., \& Kuraishi, Y. (2003). Nitric oxide enhances substance P-induced itch-associated responses in mice. British Journal of Pharmacology, 138(1), 202-08. [DOI:10.1038/sj.bjp.0705004] [PMID] [PMCID]

Ayajiki, K., Fujioka, H., Okamura, T., \& Toda, N. (2001). Relatively selective neuronal nitric oxide synthase inhibition by 7-nitroindazole in monkey isolated cerebral arteries. European Journal of Pharmacology, 423(2-3), 179-83. [DOI:10.1016/S00142999(01)01068-8]

Azad, S. C., Marsicano, G., Eberlein, I., Putzke, J., Zieglgansberger, W., \& Spanagel, R., et al. (2001). Differential role of the nitric oxide pathway on $\triangle 9$-THC-induced central nervous system effects in the mouse. European Journal of Neuroscience, 13, 561-8. [DOI:10.1046/j.1460-9568.2001.01431.x] [PMID]

Banafshe, H. R., Ghazi-Khansari, M., \& Dehpour, A. R. (2005). The effect of cyclosporine on the development and expression of cannabinoid tolerance in mice. Pharmacol Biochem Behav, 82(4), 658-63. [DOI:10.1016/j.pbb.2005.11.006] [PMID]

Boucher, J. L., Moali, C., \& Tenu, J. P. (1999). Nitric oxide biosynthesis, nitric oxide synthase inhibitors and arginase competition for L-arginine utilization. Cellular and Molecular Life Sciences, 55(8-9), 1015-28. [DOI:10.1007/s000180050352] [PMID]

Carney, S. T., Lloyd, M. L., MacKinnon, S. E., Newton, D. C., Jones, J. D., \& Howlett, A. C., et al. (2009). Cannabinoid regulation of nitric Oxide Synthase I (nNOS) in neuronal cells. Journal of Neuroimmune Pharmacology, 4(3), 338-49. [DOI:10.1007/ s11481-009-9153-7] [PMID] [PMCID]

Cevikbas, F., Steinhoff, M., \& Ikoma, A. (2011). Role of spinal neurotransmitter receptors in itch: new insights into therapies and drug development. Cns Neuroscience \& Therapeutics, 17(6), 742-9. [DOI:10.1111/j.1755-5949.2010.00201.x] [PMID] [PMCID]

Darmani, N. A., \& Pandya, D. K. (2000). Involvement of other neurotransmitters in behaviors induced by the cannabinoid CB1 receptor antagonist SR 141716A in naive mice. Jour- 
nal of Neural Transmission, 107(8-9), 931-45. [DOI:10.1007/ s007020070043] [PMID]

Duncan, A. J., \& Heales, S. J. (2005). Nitric oxide and neurological disorders. Molecular Aspects of Medicine, 26(1-2), 67-96. [DOI:10.1016/j.mam.2004.09.004] [PMID]

Dvorak, M., Watkinson, A., McGlone, F., \& Rukwied, R. (2003). Histamine induced responses are attenuated by a cannabinoid receptor agonist in human skin. Inflammation Research 52(6), 238-45. [DOI:10.1007/s00011-003-1162-z] [PMID]

Foroutan, A., Haddadi, N. S., Ostadhadi, S., Sistany, N., \& Dehpour, A. R. (2015). Chloroquine-induced scratching is mediated by NO/cGMP pathway in mice. Pharmacology Biochemistry and Behavior, 134, 79-84. [DOI:10.1016/j.pbb.2015.04.016] [PMID]

Grotenhermen, F., \& Muller-Vahl, K. (2012). The therapeutic potential of cannabis and cannabinoids. Deutsches Arzteblatt International, 109(29-30), 495-501 [DOI:10.3238/arztebl.2012.0495] [PMID] [PMCID]

Gunduz, O., Topuz, R. D., Karadag, C. H., \& Ulugol, A. (2016) Analysis of the anti-allodynic effects of combination of a synthetic cannabinoid and a selective noradrenaline re-uptake inhibitor in nerve injury-induced neuropathic mice. European Journal of Pain, 20(3), 465-71. [DOI:10.1002/ejp.752] [PMID]

Gunduz, O., Topuz, R. D., Todurga, Z. G., Duvan, K., Karadag, C. H., \& Ulugol, A. (2015). Effect of activation of the GLT-1 transporter by a beta-lactam antibiotic on serotonin-induced scratching behavior in mice. Neurophysiology, 47(1), 36-9. [DOI:10.1007/s11062-015-9494-1]

Janoyan, J. J., Crim, J. L., \& Darmani, N. A. (2002). Reversal of SR 141716A-induced head-twitch and ear-scratch responses in mice by Delta(9)-THC and other cannabinoids. Pharmacology Biochemistry and Behavior, 71(1-2), 155-62. [DOI:10.1016/ S0091-3057(01)00647-5]

Jones, J. D., Carney, S. T., Vrana, K. E., Norford, D. C., \& Howlett, A. C. (2008). Cannabinoid receptor-mediated translocation of NO-sensitive guanylyl cyclase and production of cyclic GMP in neuronal cells. Neuropharmacology, 54(1), 23-30. [DOI:10.1016/j.neuropharm.2007.06.027] [PMID] [PMCID]

Lucas, P. (2012). Cannabis as an adjunct to or substitute for opiates in the treatment of chronic pain. Journal of Psychoactive Drugs, 44(2), 125-133. [DOI:10.1080/02791072.2012.684624] [PMID]

Maccarrone, M., Bab, R., Biro, T., Cabral, G. A., Dey, S. K., \& Di Marzo, V., et al. (2015). Endocannabinoid signaling at the periphery: 50 years after THC. Trends in Pharmacological Sciences, 36(5), 277-96. [DOI:10.1016/j.tips.2015.02.008] [PMID] [PMCID]

Morita, T., McClain, S. P., Batia, L. M., Pellegrino, M., Wilson, S. R., \& Kienzler, M. A., et al. (2015). HTR7 Mediates Serotonergic Acute and Chronic Itch. Neuron, 87(1), 124-38. [DOI:10.1016/j.neuron.2015.05.044] [PMID] [PMCID]

Nakamura, A., Fujita, M., \& Shiomi, H. (1996). Involvement of endogenous nitric oxide in the mechanism of bradykinininduced peripheral hyperalgesia. British Journal of Pharmacology, 117(3), 407-12. [DOI:10.1111/j.1476-5381.1996.tb15205.x] [PMID] [PMCID]

Olah, A., Szekanecz, Z., \& Biro, T. (2017). Targeting Cannabinoid Signaling in the Immune System: "High"-ly Exciting
Questions, Possibilities, and Challenges. Frontiers in Immunology, 8. [DOI:10.3389/fimmu.2017.01487] [PMID] [PMCID]

Ormerod, A. D., Weller, R., Copeland, P., Benjamin, N., Ralston, S. H., \& Grabowksi, P., et al. (1998). Detection of nitric oxide and nitric oxide synthases in psoriasis. Archives of Dermatological Research, 290(1-2), 3-8. [DOI:10.1007/s004030050268] [PMID]

Ostadhadi, S., Haj-Mirzaian, A., Azimi, E., Mansouri, P., \& Dehpour, A. R. (2015). Involvement of nitric oxide in serotonin-induced scratching in mice. Clinical and Experimental Dermatology, 40(6), 647-52. [DOI:10.1111/ced.12605] [PMID]

Prevot, V., Rialas, C. M., Croix, D., Salzet, M., Dupouy, J. P., \& Poulain, P., et al. (1998). Morphine and anandamide coupling to nitric oxide stimulates GnRH and CRF release from rat median eminence: neurovascular regulation. Brain Research 790(1-2), 236-44. [DOI:10.1016/S0006-8993(98)00066-3]

Ross, S. E. (2011). Pain and itch: insights into the neural circuits of aversive somatosensation in health and disease. Cur rent Opinion in Neurobiology, 21(6), 880-887. [DOI:10.1016/j. conb.2011.10.012] [PMID]

Saglam, G., Gunduz, O., \& Ulugol, A. (2014). Blockade of cannabinoid $\mathrm{CB} 1$ and $\mathrm{CB} 2$ receptors does not prevent the antipruritic effect of systemic paracetamol. Acta Neurologica Belgica, 114(4), 307-9. [DOI:10.1007/s13760-013-0272-9] [PMID]

Schlosburg, J. E., Boger, D. L., Cravatt, B. F., \& Lichtman, A. H. (2009). Endocannabinoid modulation of scratching response in an acute allergenic model: a new prospective neural therapeutic target for pruritus. Journal of Pharmacology And Experimental Therapeutics, 329(1), 314-23. [DOI:10.1124/ jpet.108.150136] [PMID] [PMCID]

Schlosburg, J. E., O'Neal, S. T., Conrad, D. H., \& Lichtman, A. H. (2011). CB1 receptors mediate rimonabant-induced pruritic responses in mice: investigation of locus of action. Psychopharmacology, 216(3), 323-331. [DOI:10.1007/s00213-011-2224-5] [PMID] [PMCID]

Schmelz, M. (2010). Itch and pain. Neuroscience and Biobehavioral Reviews, 34(2), 171-6. [DOI:10.1016/j.neubiorev.2008.12.004] [PMID]

Snyder, S. H., \& Bredt, D. S. (1991). Nitric oxide as a neuronal messenger. Trends in Pharmacological Sciences, 12(4), 125-8. [DOI:10.1016/0165-6147(91)90526-X]

Spina, E., Trovati, A., Parolaro, D., \& Giagnoni, G. (1998). A role of nitric oxide in WIN 55,212-2 tolerance in mice. European Journal of Pharmacology, 343(2-3), 157-63. [DOI:10.1016/S00142999(97)01543-4]

Spradley, J. M., Davoodi, A., Gee, L. B., Carstens, M. I., \& Carstens, E. (2012). Differences in peripheral endocannabinoid modulation of scratching behavior in facial vs. spinally-innervated skin. Neuropharmacology, 63(4), 743-9. [DOI:10.1016/j.neuropharm.2012.05.032] [PMID] [PMCID]

Taniuchi, S., Kojima, T., Hara, K., Yamamoto, A., Sasai, M., \& Takahashi, H., et al. (2001). Increased serum nitrate levels in infants with atopic dermatitis. Allergy, 56(7), 693-5. [DOI:10.1034/j.1398-9995.2001.00131.x] [PMID]

Thorat, S. N., \& Bhargava, H. N. (1994). Effects of NMDA receptor blockade and nitric-oxide synthase inhibition on the acute and chronic actions of delta(9)-tetrahydrocannabinol 
in mice. Brain Research, 667(1), 77-82. [DOI:10.1016/00068993(94)91715-9]

Todurga, Z. G., Gunduz, O., Karadag, C. H., \& Ulugol, A. (2016). Descending serotonergic and noradrenergic systems do not regulate the antipruritic effects of cannabinoids. Acta Neuropsychiatr, 28(6), 321-6. [DOI:10.1017/neu.2016.16] [PMID]

Tosun, N. C., Gunduz, O., \& Ulugol, A. (2015). Attenuation of serotonin-induced itch responses by inhibition of endocannabinoid degradative enzymes, fatty acid amide hydrolase and monoacylglycerol lipase. Journal of Neural Transmission, 122(3), 363-7. [DOI:10.1007/s00702-014-1251-x] [PMID]

Ulugol, A. (2014). The endocannabinoid system as a potential therapeutic target for pain modulation. Balkan Medical Journal, 31, 115-20. [DOI:10.5152/balkanmedj.2014.13103] [PMID] [PMCID]

Ulugol, A., Aslantas, A., Karadag, H. C., Bulbul, E. D., Tuncer, A., \& Dokmeci, I. (2002). The effect of combined systemic administration of morphine and L-name, a nitric oxide synthase inhibitor, on behavioral signs of neuropathic pain in rats. Neuroscience Research Communications, 30(3), 143-53. [DOI:10.1002/nrc.10026]

Ulugol, A., Karadag, H. C., Ipci, Y., Tamer, M., \& Dokmeci, I. (2004). The effect of WIN 55,212-2, a cannabinoid agonist, on tactile allodynia in diabetic rats. Neuroscience Letters, 371(2-3), 167-70. [DOI:10.1016/j.neulet.2004.08.061] [PMID]

Ulugol, A., Topuz, R. D., Gunduz, O., Kizilay, G., \& Karadag, H. C. (2016). Changes in nociceptin/orphanin FQ levels in rat brain regions after acute and chronic cannabinoid treatment in conjunction with the development of antinociceptive tolerance. Fundam Clin Pharmacol, 30, 537-48. [DOI:10.1111/ fcp.12215] [PMID]

Zhang, N., Diao, Y., Hua, R. R., Wang, J., Han, S., \& Li, J. F., et al. (2017). Nitric oxide-mediated pathways and its role in the degenerative diseases. Frontiers in Bioscience-Landmark, 22, 824-34. [DOI:10.2741/4519] [PMID] 